\title{
Geological photogrammetry using standard colour slides
}

\author{
Keld S. Dueholm and Adam A. Garde
}

Photogrammetric mapping methods (Dueholm, 1979; Jepsen \& Dueholm, 1978; Pedersen, 1981) are widely used by the Geological Survey of Greenland (GGU). However, until now it has only been possible to use vertical aerial photographs taken with large frame photogrammetric cameras. As a major part of the geology in Greenland is exposed on steep mountain sides, there are many areas that cannot be mapped from vertical aerial photographs. In 1983 a research project was set up to investigate photogrammetric mapping using commercially available oblique aerial photographs, as well as terrestrial photographs taken by geologists with ordinary $24 / 36 \mathrm{~mm}$ cameras (fig. 1). A new type of photogrammetric instrument, the Kern DSR11/GP1 Analytical Plotter, was procured for this and other projects. Here we present results and experience from the first successful mapping in Greenland with an ordinary $24 / 36 \mathrm{~mm}$ camera.

\section{Project area}

In the summer of $1985 \mathrm{~A}$. A. G. carried out detailed geological mapping at the Store Malene mountain near Nuuk during a study of tungsten mineralisation in the Archaean Malene supracrustal rocks (Appel \& Garde, this volume). The field work was preceded by photo-

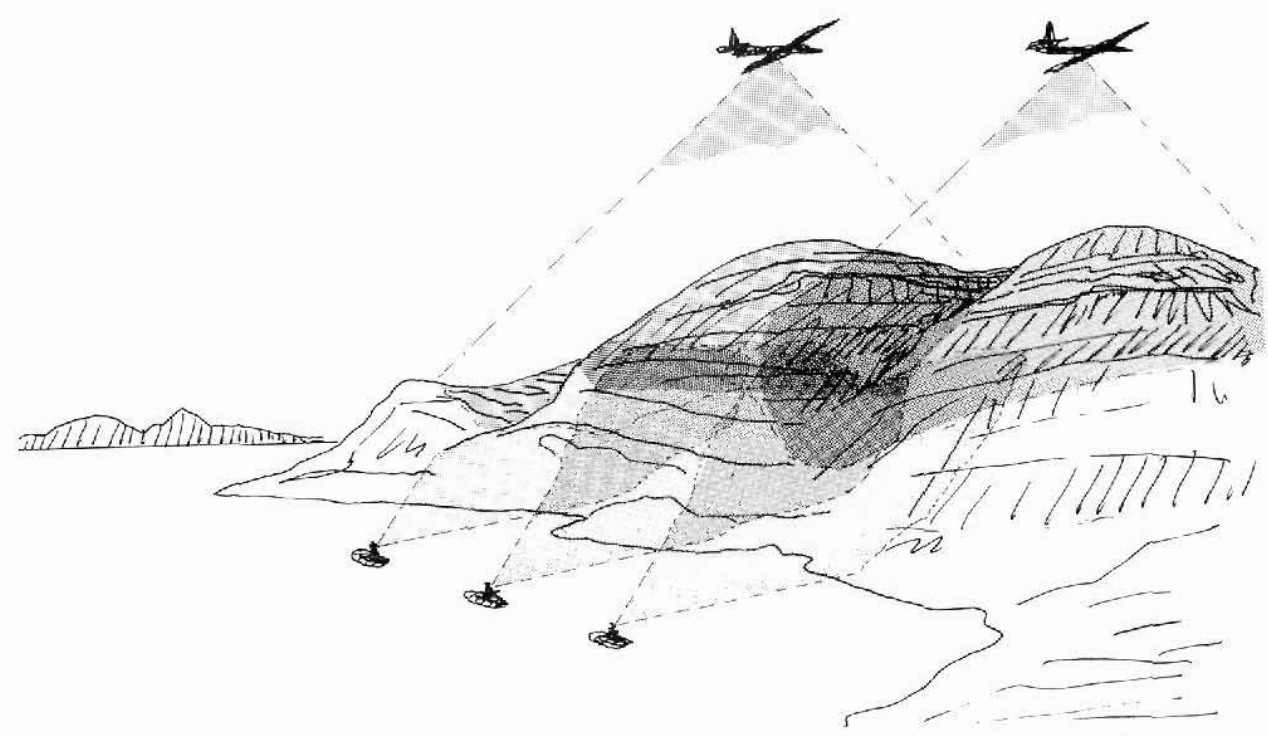

Fig. 1. Photographing the Store Malene mountain from a rubber dinghy in Kobbefjord with an ordinary, hand-held camera. The vertical aerial photographs used in the project are shown schematically. Sketch by O. Jacobi, ILF. 
geological interpretation and plotting from vertical aerial photographs at a scale of $c$. 1:10 000, using the Kern PG2 photogrammetric plotting instrument and attached plotting table at GGU. Some of the mineralised horizons and cross-cutting pegmatites crop out on steep mountain sides facing Kobbefjord to the south-east. The coverage of these mountain faces is very poor on the vertical photographs, due to an unfavourable position of the route of flying.

Several circumstances rendered the Store Malene area suitable for an experiment in handheld terrestrial geological photogrammetry: the good quality and appropriate scale of the existing vertical aerial photographs (necessary for transference of orientation points, see below), the many geological features visible on the mountain faces, the need to fill the geological gaps left after mapping from the vertical photographs, and the good accessibility of the area.

\section{Hand-held photography}

An Olympus OM-1 24/36 mm camera with a wide angle lens ( $f=35 \mathrm{~mm}, 1: 2.8)$ and 64 ASA Kodachrome diapositive film was used. The photographs were taken in 1985 by a geologist from a rubber dinghy in Kobbefjord sailing along the coastline at a distance of about $1.5 \mathrm{~km}$ from the outcrops of interest. The resulting scale of the diapositives is $c .1: 40000$. Photographs were taken as parallel as possible with an overlap of about $80 \%$, which secured stereoscopic coverage of the mountain side. Fig. 1 shows the situation during photography, and one of the stereo pairs is shown in fig. 2. Photo overlap and camera orientation were judged by eye so that the camera was the only instrument used. The wide angle lens facilitated the taking of parallel photographs: slanting lines immediately appeared when the camera was not directed perpendicularly to the mountain face.

In order to reestablish the exact focal length to be used in the subsequent photogrammetric measurements, the lens must be focused on infinity for photography. It is also important that the mountain side fills out the frame as much as possible to help the orientation of the photographs in the analytical plotter. The latter demand, combined with the choice of a wide angle lens gives practical problems in this project. The photographs have to be taken at a relatively short distance, and since the geology of interest is exposed at the top of the cliff, it is difficult to avoid hidden areas. Oblique photographs taken from a helicopter during camp move would be ideal to solve this particular problem.
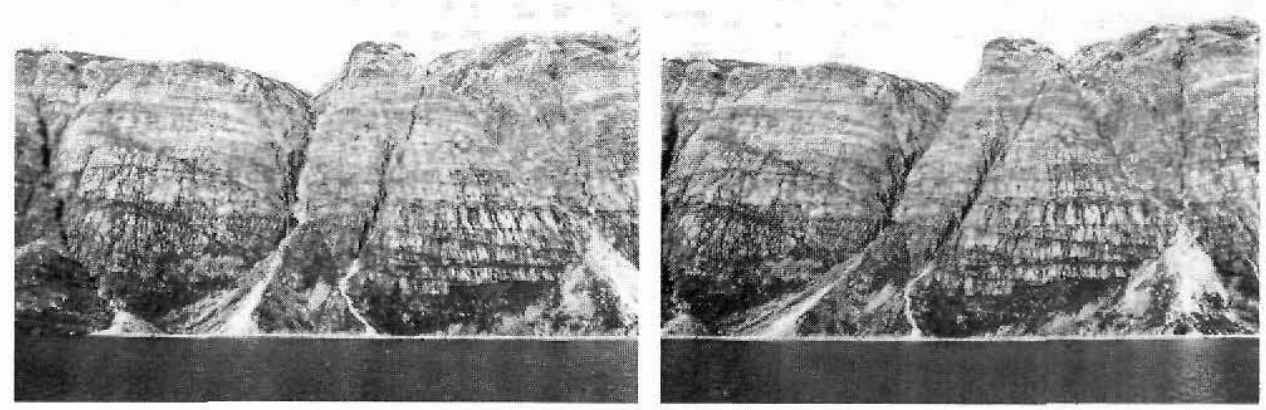

Fig. 2. Stereo pair of field photographs used for photogrammetric measurements at Store Malene. 


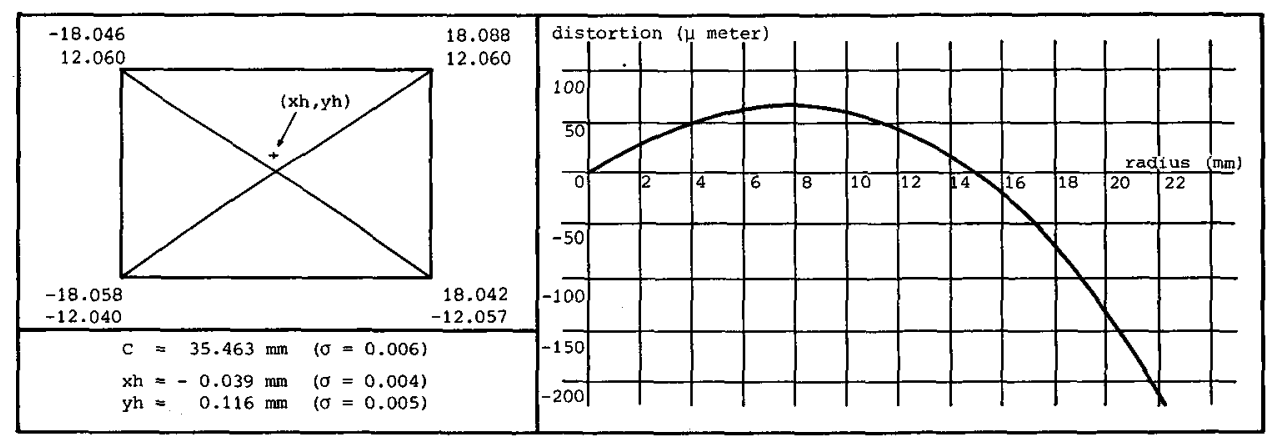

Fig. 3. Calibration data of the Olympus OM-1 $24 / 36 \mathrm{~mm}$ camera no. 642694 (GGU 1-09) with $35 \mathrm{~mm}$ lens 1:2.8 no. 208606. The corner coordinates and principal point $(x h, y h)$ of a photograph, as well as the distortion curve and focal length (c) of the lens are shown. Note the large distortion at the photo corners, which is eliminated during the photogrammetry. The maximum standard deviation of the distortion curve is 6 microns at radius $=22 \mathrm{~mm}$.

\section{Instrumentation}

The Kern DSR11 Analytical Plotter is a photogrammetric plotting instrument for plotting continuous lines from a stereoscopic model, like the Kern PG2 instrument at GGU. However, in the analytical plotter, model orientation and plotting is completely computer-controlled. There are no mechanical components to limit the photogrammetric parameters (e.g. focal length, camera lens distortion, and tilt angles) and computer programs can be worked out to accommodate any parameter value. System software for the instrument is still under development by K. S. D.

\section{Photogrammetric procedure}

The camera was calibrated at the Institute of Surveying and Photogrammetry (ILF). This is done by photographing a test field of 117 coordinated points in the laboratory. The radial distortion of the lens, the exact focal length at infinity, and the principal point of the photograph are determined by a least-squares adjustment of the test field points measured in the photographs. The whole procedure takes about half a day. The results of the calibration are shown in fig. 3 . The lens distortion is more than 200 microns at the corners of the photographs, but the standard error of the residuals after calibration is only 4 microns on the photo scale.

The field photographs were now orientated in the analytical plotter by means of programs that create a distortion-free stereoscopic model based on the calibration data. At least three control points are needed to orientate each terrestrial model. Such points were identified in the corresponding vertical aerial photographs, and their coordinates were measured in the analytical plotter. For experimental reasons, 6 to 12 points were transferred for each of the seven stereo models set up in this project. The terrestrial models were seen under 20 times enlargement in the analytical plotter on a viewing scale of about 1:2000. The map sheet with geology drawn from the aerial photographs was orientated on the plotting table attached to 


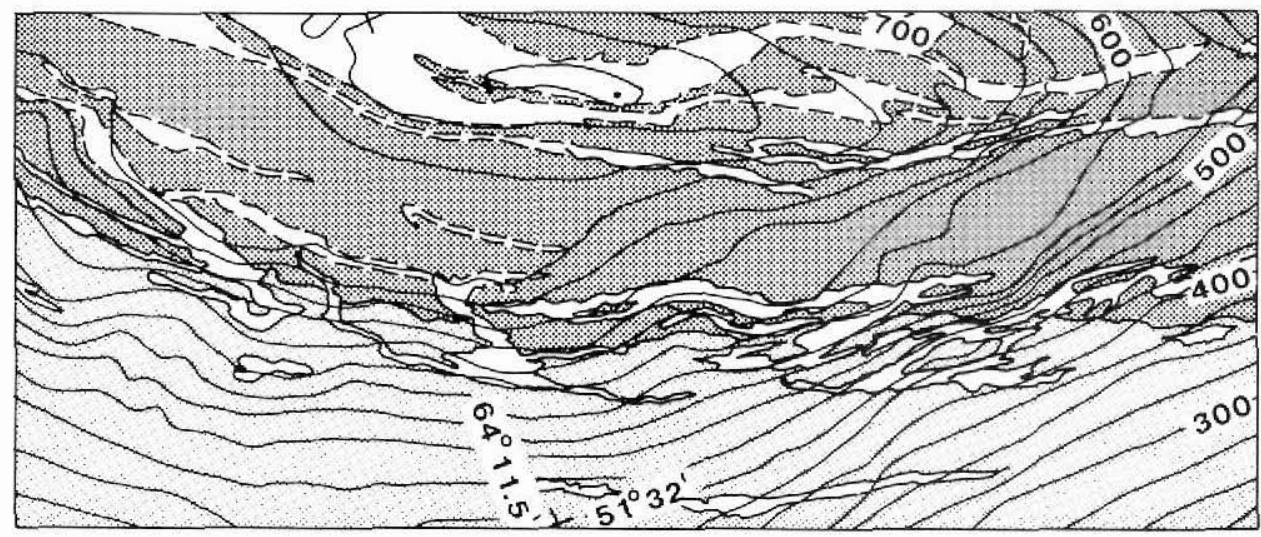

Fig. 4. Part of a geological map of Store Malene (scale 1:7500) with geology drawn from vertical aerial photographs (stippled lines) and terrestrial hand-held diapositives (full lines). Dark: supracrustal rocks, light: gneiss, no signature: pegmatite.

the instrument, and the desired geological features were then plotted on an overlay by the geologist.

\section{Accuracy}

The absolute standard deviation of the orientation of the small frame photographs was about $1.5 \mathrm{~m}(1 \sigma)$ on the ground scale. In the orientated model, relative measurements could be taken with a standard deviation of less than $40 \mathrm{~cm}$. A small portion of the produced map is shown in fig. 4. The full lines were plotted from the terrestrial models and the stippled lines from the aerial photographs. No systematic discrepancies are observed on the map scale shown $(1: 7500)$.

\section{Discussion}

Theoretically, the absolute standard deviation $(1.5 \mathrm{~m})$ can be improved to about $40 \mathrm{~cm}$. This will be attempted during future work. Two error sources are likely in the present work: (a) identification and transfer of control points from the vertical photographs could result in errors of this magnitude, (b) residual model distortions are likely to be present because the mountain side does not completely fill out the frame of the photographs. This makes the relative orientation of the photogrammetric model very sensitive. However the $1.5 \mathrm{~m}$ absolute standard deviation is sufficiently small for the purpose of this project.

The acquisition of orientation control by transfer of points from vertical aerial photographs is possible but time consuming. It is difficult to identify topographic features precisely under the grossly different angles of view in the vertical and the terrestrial models. Characteristic geological features seem to be the best choice, but this implies that the geologist has to be involved in the orientation process. Once the control points are identified and measured, the setting up of one terrestrial model is a matter of 10-20 minutes.

More advanced orientation programs based on self-calibrating bundle adjustments are be- 
ing developed to facilitate the transfer and cut down the number of points needed. These programs will make it possible to orientate a whole strip of photographs and simultaneously use additional information from the field. In the present project the photographs were taken $1 \mathrm{~m}$ above sea level. The incorporation of this information would greatly strengthen the orientation, and probably only one transferred point every two or three models would be needed. The above mentioned sensitivity of the relative orientation should also be solved by means of this program.

Several other geologists have taken photographs in the field during the summers of 1984 and 1985. Henrik Højmark (GGU) and Martin Heinesen (Geological Museum) were involved in early experiments that failed because of inadequate computer programs. These and other projects will now be taken up in order to outline further specific demands on software and field photography.

\section{Conclusions}

It is possible to use terrestrial small frame photographs taken by geologists in the field with ordinary cameras for photogrammetric drawing of high precision geological maps. Control points necessary for orientation of the small frame photographs can be transferred from aerial photographs.

The use of normal commercial 64 ASA colour slide film enables an effective enlargement of the photographs of at least 20 times in the instrument. The choice of a wide angle lens (35 $\mathrm{mm}$ ) was good for geometrical accuracy and stereo effect. The lens distortion found by the calibration is large, but apparently consistent and therefore can be eliminated by the mathematics. However, in this project a standard $(f=50-55 \mathrm{~mm})$ lens would have been preferable for the geological interpretation, permitting a more favourable angle of view to the top of the mountain side.

For the geologist the use of photographs taken by himself from land, boat or helicopter during (or ideally before) field work has many advantages. The scale of photography, the angle of view, and time of the day can be chosen at will according to the demands of the problem at hand. Photographs in colours have an obvious advantage. Many geological structures, especially flat-lying ones, are readily interpreted and drawn from terrestrial photographs with angles of view that resemble the field work situation. In this project black and white prints of $24 / 36 \mathrm{~mm}$ photographs were employed in the field during mapping of cliff faces but in some cases hand sketches might be sufficient, combined with terrestrial stereo photographs for subsequent geological photogrammetry in the laboratory.

The method, when fully developed, is a very efficient way of covering areas that cannot be mapped from aerial photographs because of steep terrain and/or shadows. The method will certainly also be of value in detailed studies of selected areas or when drawing detailed maps, sections and profiles.

Acknowledgements. The project is carried out in co-operation between GGU and the Institute of Surveying and Photogrammetry (ILF) at the Technical University of Denmark, and is supported by the Danish Natural Science Research Council and the Danish Technical Science Research Council. 


\title{
References
}

Dueholm, K. S. 1979: Geological and topographic mapping from aerial photographs. Medd. Inst. Surv. Photogrammetry, Danm. Tekn. Højsk. 10, 204 pp.

Jepsen, H. F. \& Dueholm, K. S. 1978: Computer supported geological photointerpretation. Rapp. Grønlands geol. Unders. 90, 146-150.

Pedersen, S. A. S. 1981: The application of computer-assisted photogrammetric methods in the structural analysis of part of the North Greenland Fold Belt. J. Struct. Geol. 3, 253-264.

K. S. D., Instituttet for Landmåling og Fotogrammetri, Danmarks Tekniske Højskole, Landmålervej 7 , DK-2800 Lyngby, Denmark.

\section{Malene stratigraphy and late Archaean structure: new data from Ivisârtoq, inner Godthåbsfjord, southern West Greenland}

\author{
Brian Chadwick
}

This report summarises the principal results of a six-week study of some critical areas in Ivisârtoq (part of the Ivisârtoq region, 65 V. 2 Nord; fig. 1) by a two-man expedition (the writer and his undergraduate assistant) during the summer of 1985, a period of exceptionally good weather. Our objective was to complete the field programme of a team from the University of Exeter (Chadwick et al., 1983; Brewer et al., 1984) which had been seriously disrupted by bad weather in 1983 . The main thrust of the field work in 1985 was to investigate the geometry of the late Archaean system of domes of gneisses and intervening synclinal cusps of Malene supracrustal rocks which dominates the structure of Ivisârtoq (figs 1,2). The field mapping revealed important new details, not only of the structure but also of the Malene stratigraphy and the emplacement of granitic and basaltic magmas during the development of the system of domes and synclines.

Systematic geological investigations in the Ivisârtoq region began in 1976 (Allaart et al., 1977 ) and important contributions have been made by Hall \& Friend $(1979,1983)$, Hall $(1980,1981)$ and Friend et al. (1981). Some preliminary results of investigations by the Exeter team have been reported by Brewer et al. (1984), Chadwick (1985), and Coe \& Robertson (1984). Details of isotopic ages and petrogenesis of the gneisses and late Archaean granites have been reported by Robertson (1985, in press).

\section{Malene stratigraphy}

The most complete section of the Malene stratigraphy is preserved in the southern limb of the asymmetric syncline in southern Ivisârtoq (figs $1,2,3,4$ ). The attenuation of the stratigraphy on the northern limb (fig. 3) may be an effect of rapid variation in the original thick- 